\title{
An Empirical Research on Self-learning Vocabulary
}

\author{
Luu Trong Tuan \\ University of Finance-Marketing, Vietnam \\ Email: luutrongtuan@vnn.vn
}

\begin{abstract}
This empirical study seeks to examine learners' autonomy in acquiring vocabulary. Research data collated through survey questionnaires sent to students and teachers at University of Finance-Marketing depicted learners' attitudes toward vocabulary learning autonomy as well as strategies they utilized in vocabulary learning process.
\end{abstract}

Index Terms - vocabulary learning, autonomy, EFL

\section{INTRODUCTION}

Vocabulary is a component that links the four skills of speaking, listening, reading and writing together. According to Krashen (1989), the reasons for devoting attention to vocabulary are: "First, a large vocabulary is of course essential for mastery of a language. Second, language acquirers know this; they carry dictionaries with them, not grammar books, and regularly report that the lack of vocabulary is a major problem". In other words, the more vocabulary a language learner has, the better they are considered to master the language. However, Sokmen (1997) notes that it is impossible for students to learn all the vocabulary they need in the classroom since there are so many words on which teachers can not spend time within the class time limit; thus, vocabulary expanding process requires the higher level of autonomy as well as more responsibility from learners themselves.

As such, the current English learning of first year students of University of Finance-Marketing proves to be "undesirable" due to their lack of autonomy in vocabulary learning; and the importance of vocabulary learning autonomy needs to be undescored. The students need to realize that success in learning depends much on their own efforts, like the way Scharle and Szabó state: "Success in learning very much depends on learners taking responsibility" (2000, p. 4). The truth that responsibility accepted in learning by the students at University of Finance-Marketing is what teachers have dreamt about. In such a situation, this research aimed to examine how the students at University of Finance-Marketing learn vocabulary autonomously. The questions guiding this research encompass:

1) What are the attitudes of first year students of University of Finance-Marketing towards autonomy in vocabulary learning?

2) What strategies are employed by those students in enriching vocabulary autonomously?

3) What strategies are frequently used by the teachers in order to nurture learner autonomy in learning vocabulary for the first year students of University of Finance-Marketing?

\section{LITERATURE REVIEW}

\section{A. Approaches to Vocabulary Learning}

Following are three approaches to vocabulary instruction and learning discussed by Hunt and Beglar (2002): incidental vocabulary learning, explicit instruction, and independent strategy development.

\section{Incidental vocabulary learning}

The incidental vocabulary learning is defined by Nation (2001) as one of the important strategies in vocabulary acquisition. It refers to the fact that a person can expand his or her vocabulary knowledge while being involved in any language activities without any specific intention to focus on vocabulary. This method includes learning from joining conversations; listening to radio, stories, music; watching movies, television; especially extensive reading; or any other exposure of input and output both in and out of the classrooms (Nation, 2001). As such, incidental vocabulary learning is generally acknowledged as learning words mainly in context (Nation, 1990). Therefore, Krashen (1989) suggests that incidental or uninstructed vocabulary learning takes place in both native and nonnative languages as well.

\section{Explicit vocabulary learning}

A traditional and common method in teaching vocabulary is explicit vocabulary learning. Nation (1990) puts it that it helps to fill the gap of vocabulary size between native speakers and second or foreign language learners within a short period of time.

Nation (1990) demonstrates that explicit attention is given to direct vocabulary learning. That means learners are specially instructed to pay their attention directly on activities in which vocabulary acquisition occurs immediately. As such, explicit, intentional or direct vocabulary learning is the method of acquiring vocabulary by using tools to lead the 
learner's focusing on direct contact with the form and meaning of words; for example, dictionary use, vocabulary lists and their translations, direct vocabulary explanations, learning affixes and roots, semantic mapping and matching words with different definitions, etc. Hunt and Beglar (2002) put it that explicit instruction (direct vocabulary instruction) includes identifying the words learner need to know, presenting words for the first time, elaborating word knowledge, and developing fluency with known words.

In a nutshell, explicit vocabulary learning is recognized as subscale including strategies of rote memorization, reliance on L1, and a metacognitive part of regular and planned revision. In spite of the fact that this method of learning gives the greatest opportunity for acquisition, as well as that this method of teaching vocabulary considerably contributes to vocabulary development especially for the elementary learners, those who have a limited reading vocabulary and little exposure to incidental vocabulary learning outside of school (Coady, 1997), it is too arduous for learners to follow. Moreover, intentional vocabulary teaching in classrooms is often the teacher-centered class, a traditional method in teaching vocabulary (Schmitt, 2000).

\section{Independent strategy development}

Nunan (1999) puts it that independent vocabulary learning mainly deals with practicing students to guess from context and training learners with dictionary use. According to him, language should be best come across in contexts and then acquired from contexts. So, in class, instructors should focus learners on developing the strategies for inferring the meaning of new lexical items from the context where they suggest themselves; as well as encourage learners to learn the use of a variety of clues, like verbal and non-verbal such as affixes and roots; pictures, diagrams, charts, or semantic links, etc. to determine the meaning.

The significance of context is also strongly highlighted by Honeyfield (1997 cited in Nunan, 1999) and Sokmen (1997) in learning and teaching vocabulary. It is argued that it is a lot better to train learners to employ strategies for inferring the meaning of new vocabulary from the context than to make them try to memorize time-consuming long lists of lexical items or to get them to look up new vocabulary in dictionaries.

\section{B. Schmitt's Taxonomy of Second Language Vocabulary Learning}

Schmitt (1997)'s taxonomy of second language vocabulary learning strategies is divided into two main groups: discovery and consolidating strategies which distinguish the ones to determine a word's meaning when encountered for the first time; and those helpful to consolidate the word when met again.

Category 1: Strategies for the discovery of a new word's meaning

- Determination strategies

- Analyze part of speech;

- Analyze affixes and roots;

- Check for L1 cognate;

- Analyze any available pictures or gestures;

- Guess meaning from textual context;

- Use a dictionary (bilingual or monolingual)

- Social strategies

- Ask teacher for a synonym, paraphrase, or L1 translation of new word;

- Ask classmate for meaning

Category 2: Strategies for consolidating a word once it has been encountered

- Social strategies

- Study and practice meaning in a group;

- Interact with native speaker

- Memory strategies

- Connect word to a previous personal experience;

- Associate the word with its coordinates;

- Connect the word in its synonyms and antonyms;

- Use semantic maps;

- Image word's meaning;

- Use Keyword Method;

- Group words together to study them;

- Study the spelling of a word;

- Say new word aloud when studying;

- Use physical action when learning a word

- Cognitive strategies

- Verbal repetition;

- Written repletion;

- Word lists;

- Put English labels on physical objects;

- Keep a vocabulary notebook 
- Metacognitive strategies

- Use English-language media (songs, movies, newscasts, etc.);

- Test oneself with word tests;

- Skip or pass new word;

- Continue to study word over time

Schmitt involves the social strategies in both categories because they are applied for different purposes. That is, for Schmitt (1997, p. 205), the determination strategies are employed when learners "are faced with discovering a new word's meaning without resource to another person's experience". But another way to discover a new meaning is through using the social strategies if asking somebody for help. Besides the preliminary finding of a word, learners still have to use a variety of other strategies in order to consolidate vocabulary knowledge. Therefore, cooperative group study is one of the examples of the social strategies to practice and retain vocabulary. Memory strategies, by tradition, known as Mnemonics, entails connecting the word with some previously old knowledge by employing some form of imaginary or grouping. The cognitive strategies, to Schmitt, are a little like the memory strategies but they are not focused on manipulative mental processing. It means that they only involve repetition and using mechanical ways like word lists, flash cards, or vocabulary notebooks. Lastly, Schmitt defines metacognitive strategies as the ones used by learners to control and assess their own learning. According to Schmitt, a typical example of metacognitive strategies is testing oneself which can provide "input to the effectiveness of one's choice of learning strategies, providing positive reinforcement if progress is being made or a signal to switch strategies if it is not".

\section{Learner Autonomy and Vocabulary Learning}

\section{What is learner autonomy?}

Nunan (2000) and Benson (2001) agree that learner autonomy is an ability to put one's own study into effect. According to Nunan (1997, p.193), "fully autonomous learner operates independently of classroom, teacher or textbooks". Palfreyman's point of view is in contrast with that: "learner autonomy does not mean avoiding any reliance on sources of help around you", but it means being conscious of those sources and what others you have in various situations. One example for this can be illustrated as follows: when a student asks his or her teacher for explaining the meaning of a new word, it is regarded as teacher dependence. But in case he or she asks teachers to certify the distinction of some synonyms he or she gets after looking up dictionaries or other sources of reference, it is learner autonomy. It is clear that the student employs the teacher as a source of help, efficiently bringing the teacher into his or her own learning agenda. Thanasoulas (2000) seems to share the idea with Nunan when he concludes that autonomous learner is one who can independently select aims and purposes; can set goals; can choose materials, methods and tasks; then can apply those choices and purposes in organizing and executing the selected tasks, and can choose the evaluation criteria for one's final work.

\section{Learner autonomy and vocabulary learning}

Vocabulary learning is very significant to foreign language acquisition. It is impossible for a learner to communicate without the needed vocabulary. No doubt that a learner cannot learn all language vocabulary in class, so he is forced to find other ways to learn vocabulary. Learner autonomy is a great relief for students in vocabulary learning because it provides the learner with many privileges as:

- Learner autonomy enhances the learner's motivation and leads to more effective vocabulary learning.

- Learner autonomy provides learners with more opportunities for language communication in a non-native environment.

- Learner autonomy caters to the individual needs of learners at all levels.

- Learner autonomy has a lasting influence.

- Learner autonomy enhances the learner to master the basic skills that are required to lasting learning.

It is important to mention that if the autonomous learner is willing to be a good learner in learning vocabulary, he/she finds that there are many factors that affect their autonomy development as previous learning experiences, independent study methods, workload, role of tutor, feedback and assessment and peer group. Thus a learner should decide what kind of learning strategies he/she should adopt for the great benefit he/ she could gain it. No doubt those learners are in need to be taught how to learn vocabulary, rather than simply the vocabulary items themselves. Here learning strategies are good indicators of how learners approach tasks or problems encountered during the process of vocabulary learning.

\section{Methodology}

\section{A. Participants}

The participants taking part in the study belonged to two groups. The first group consisted of 140 first year full-time students from four pre-intermediate general English classes at University of Finance-Marketing. The second group consisted of 13 teachers.

\section{B. Instruments}

In order to answer the research questions posed, the study's data were collected using two different questionnaires both written in Vietnamese, one for students and the other for teachers. 19-item questionnaire for students was contrived 
to elicit information on the students' background information, attitudes towards autonomous vocabulary learning, their strategies to enrich vocabulary autonomously, and their teachers' strategies to foster learner autonomy in their vocabulary learning. The 13-item questionnaire for teachers was developed with the aim to clarify the student subjects' answers in the students' questionnaire.

\section{FINDINGS AND DiSCUSSIONS}

\section{Findings for research question 1: What are the attitudes of first year students of University of Finance-Marketing towards autonomy in vocabulary learning?}

For question 4 in the students' questionnaire, the researcher focused on investigating the students' opinion of vocabulary learning. About $90.71 \%$ of them all asserted that vocabulary learning was a difficult area, only $9.29 \%$ of them considered this skill as medium.

In order to know whether or not these students can manage to improve their vocabulary by themselves outside the classroom, it was essential for the researcher to identify how students felt about the importance of vocabulary in supporting other English skills. Question 5 asked students to access in detail how much vocabulary knowledge supports their other skills in their experience. One student did not answer this question. This is a vital evidence to prove that nearly all of the students were aware of a fact that lacking vocabulary might hinder their ability's to express themselves in the target language and to make use of L2 learning opportunities (97.14\%). It means that for students, although vocabulary learning was a difficult area, it certainly played an important role in communication and acquisition as well as was really useful for mastering English.

In order to gain a general view of the students' attitudes toward vocabulary learning, question 6 investigated the level of students' interest in this field. Three out of the respondents did not give their answers. Students who showed neutral interest in vocabulary learning ranked the first among 98 students, with $70.00 \%$. It was followed by the number of students who were uninterested in vocabulary (15.00\%). The percentage of students who showed interested attitudes to vocabulary learning rather low, with just $12.86 \%$.

Being asked about the role of autonomy in vocabulary learning in question 7, 105 students (75.00\%) admitted that autonomy plays a very important role in vocabulary learning. Only 32 students (about 22.86\%) still selected "Medium", and one of them chose the options "Not important" $(0.71 \%)$. Two respondents did not give answers.

The data collected from this question showed that students understood fairly well the place of autonomy in their process of learning although this result was still lower than the result collected from the responses for question 5 of Part 1 in the teachers' questionnaire: $100 \%$ of the teachers (13) claimed that autonomy was beneficial to their students' English vocabulary. Thus, as initially reflected in both students' and teachers' attitudes toward autonomy in vocabulary learning, it could be concluded that although the majority of students asserted that vocabulary learning was very useful for mastering their English, and regarded autonomy as an indispensable factor in their English study, their level of interest in broadening their vocabulary shown from the data was only moderate. The reason for this phenomenon could be partly explained by the data collected from question 4 in the questionnaire. Obviously, in spite of their clear awareness of the important role of vocabulary and autonomy in study, the majority of students appeared quite reluctant to learn it because it was a really challenging field to master.

In terms of the goals for learning vocabulary, it is noticeable from the result of question 8 that a relatively high percentage of students identified their goal as to broaden their knowledge in major $(80.00 \%)$. $74.29 \%$ of the students want to develop their English in general and $68.57 \%$ to better their communication. However, $5.71 \%$ of the students still did not have any plans concerning their goals and $4.29 \%$ of them did not want to give answers to the researcher.

From the data collected above, the researcher can realize that whatever any plans in mind, most of their students learn vocabulary with their clear goals. Although it is happy to realize these students have goals in learning vocabulary, it is surprising to see the results of students' frequency in vocabulary learning from question 9 in Part one of students' questionnaire. The teachers were also involved in this kind of question in teachers' questionnaire. The data collected showed that the largest number (79) was to be found in the group of students who sometimes learned vocabulary autonomously $(56.43 \%)$. The number of students saying that it was rarely for them to review vocabulary experienced the second rank with $31.43 \%$ (44). There was a quite small amount of students who usually self - practiced vocabulary building, with just $8.57 \%$ (12), and only four of them could always have frequency (2.86\%). One of them did not give answer. Luckily, there was also no student saying that they never paid attention to vocabulary learning in their study. Surprising, but it is also understandable that this low frequency can be resulted from the students' neutral attitudes to vocabulary learning investigated in questions 4,5 and 6 and autonomous vocabulary learning is quite difficult for them. For the same matter, teachers' evaluation on students' frequency in reviewing and preparing before coming to class from question 6 in the questionnaire was also not high. In their opinions, only one teacher (7.69\% of them) believed that the students usually reviewed or prepared lessons before coming to class everyday. Nearly all of the teachers agreed that their students sometimes and rarely showed studiousness in reviewing or preparing lessons before coming to class (92.31\%), not showing a good habit of autonomous learning. This result is quite corresponding to the students' reports for themselves in autonomous vocabulary learning.

In question 10, students were asked to show their tendency toward motivation for their vocabulary learning. Data on their usual time to learn vocabulary does not present a high consideration for assessment and marks. Five students did 
not give answers (3.57\%). Only 15 out of 140 students stated that exams pushed them to study vocabulary (10.71\%). The highest percentage $(66.43 \%)$ learned a vocabulary item when they considered it interesting. And nearly as many as that number of students suggested that they learned vocabulary when they felt like to do so $(60.71 \%)$. In addition, 52 students $(37.14 \%)$ learned vocabulary whenever they had time. This seems to prove one thing that the students at University of Finance-Marketing showed a tendency toward intrinsic motivation.

The teachers were involved in the purpose of the above question, too. Teachers' responses in the survey, on the other hand, supported the idea of extrinsic motivation of their students. Nine teachers $(69 \%)$ answered question 7 through their questionnaire that when there was an assignment or a task, their students first showed their care for assessment and marks without a clear indicator for intrinsic motivation. The number of the teachers considered their students as enthusiastic in study or indifferent to the tasks are the same and so low ( 2 respectively, $15 \%$ for each). This also means that their students lack a continuing motive to learn vocabulary.

By and large, students reported that their interest in vocabulary learning was sometimes triggered and somewhat vague. They did their learning when they felt like doing that or when there was something special about the word. This shows a low motivation to learn vocabulary as well as a very preliminary level of learner autonomy in the students. This is also understandable thanks to the result gained in question five that the students showed a neutral attitude to vocabulary learning. On the other hand, teachers, by assuming that their students' interest was marks and assessment only, might overlook the chance to enhance their real interest in the process of vocabulary learning.

In order to explore the students' attitudes toward this issue more thoroughly, the researcher asked the students what materials they often used to build up their vocabulary in question 11. The participants' materials were evaluated according to the authenticity of the materials. As regards the students' materials use for autonomous vocabulary learning, it can be revealed that students preferred choosing inauthentic materials for building their vocabulary than authentic ones. The texts from English study books, which seem to make students feel most familiar and comfortable to learn, were by far the most common material source for them, with the highest checks of the students (92.14\%). It was followed by the texts from Internet, with the second highest checks (72.14\%). Both short and long authentic materials (newspapers/ magazine articles and books/ dictionaries) experienced low checks (13.57\% and 22.14\% respectively) in comparison with the checks of seemingly inauthentic and entertaining song lyrics (25.71\%). In short, the participants tended to use more of inauthentic materials for vocabulary learning than authentic ones.

Question 12 asks the students about what aspects they usually knew about a word. Nearly all of them knew a vocabulary item's meaning in Vietnamese, spelling and sound (97.86\% and $96.43 \%$ respectively). Only 45 out of 140 students tried to define or explain the word in English, which is thought to be an effective way to broaden vocabulary size $(32.14 \%)$. Nearly half of them knew parts of speech or structure of word (47.14\% and $45.00 \%$ respectively). Not many of them (26.43\% and $13.57 \%$ respectively) knew synonyms and antonyms. And only fifteen students cared for collocations, which are usually considered very important in knowing a word $(10.71 \%)$. This means collocations are something strange to the students. About $40.71 \%$ of the students showed that it depended on the vocabulary they wanted to know.

In comparison with teachers' responses to question 8 , there was a convergence between the teachers and students' answers when they gave their opinions on the word aspects the students usually showed to master. It can be revealed that students almost just knew Vietnamese definition, spelling and sound, which seemed to be the most dominant way to make them feel sure that they knew the English word. Very many of the students were not aware of defining the word in English as an effective way to broaden their vocabulary size. In addition, parts of speech, structure of word, synonyms and antonyms tended to be frequently neglected by them, too. And unluckily, collocations, a very important element in knowing the word, seemed to be alien in the students' habit of learning vocabulary.

In question 13 that follows, when asked about the role of teachers and students in deciding what, how and when to learn, most students supported the idea of learner-centered with the facilitation of teachers. 98 of the students $(70.00 \%)$ believed that teachers and students need to cooperate with each other in deciding what to learn, how to learn and when to learn. It is demonstrated through the students' responses that they were well aware of the benefits of cooperation and active roles of both teachers and learners in the learning process. There was a match between the students' and teachers' opinions at University of Finance-Marketing: 11 out of 13 teachers surveyed in question 9 also agreed that teachers and learners should cooperate in deciding what to learn, how to learn and when to learn vocabulary (85\%). That means the students wished to go hand in hand with teachers and the teachers also wanted to be helpful in facilitating their students' process of vocabulary learning. However, 2 of them thought that students should do that on their own (15.38\%). This can be justified with the reality that class time for language learning at university is always limited. Thus, it is difficult for them to 'go hand in hand' with their students.

Question 14 in the students' questionnaire and 10 in the teachers' questionnaire aim to ask for the perception of teachers on the students' mastery of vocabulary as well as the students' self-assessment of themselves. There was a divergence between teachers and students' responses. $76.92 \%$ of the teachers evaluated the students' mastery in vocabulary as fair while only $60.00 \%$ of the students thought of their vocabulary mastery as fair. $23.08 \%$ of the teachers stated that the students' vocabulary mastery was poor (students' selfassessment as poor was more than their teachers': $32.86 \%$ ). However, a divergence seemed to be clearer when none of the teachers stated their students' vocabulary stock was very poor or from good to very good while there was still a minority of the students $(5.00 \%)$ saying that their 
vocabulary is very poor and $1.43 \%$ reported an excellent mastery in vocabulary. Comparing two results of assessment, it can be concluded that the students did not feel very confident of their vocabulary. With reference to the characteristics of autonomous learners that have been reviewed in the literature, this result does not provide a positive picture about learner autonomy in vocabulary learning of these students.

In short, one paradox found in this part is that: although the students found their vocabulary fair or even poor or very poor, and although they understood the importance of vocabulary learning and autonomy, they still did not have a good habit of autonomous vocabulary learning in order for their goals of learning. They even had low intrinsic motivation to learn and their confidence level for vocabulary learning is also not high. They thought that vocabulary learning was hard and they self-assessed their ability for the skill as rather low. These students almost just knew Vietnamese definition and spelling, which seemed to be the most dominant way to make them feel sure that they knew the English word. Very many of the students were not aware of defining the word in English as an effective way to broaden their vocabulary size. In addition, parts of speech, structure of word, synonyms and antonyms tended to be frequently neglected by them, too. And unluckily, collocations, a very important element in knowing the word, seemed to be alien in the students' habit of learning vocabulary. Concerning vocabulary learning materials, the participants tended to use more of inauthentic materials for vocabulary learning than authentic ones. For teachers, by assuming that their students' interest was marks and assessment only, might overlook the chance to enhance their real interest in the process of vocabulary learning.

Findings for research question 2: What strategies are employed by those students in enriching vocabulary autonomously?

First of all, in question 15, the researcher aimed to find out whether or not the students had ever known how to deal with unfamiliar words to discover their meaning. The result shows that the students commonly used two groups of strategies when encounting a new word: bilingual dictionary $(92.14 \%)$ and asking for L2>L1 translation (87.14\%). These respondents' predominant belief might be that relying on bilingual dictionaries and asking for the meaning in Vietnamese could make them sure that they knew the word and resulted in better learning of vocabulary items. However, luckily, the students appeared to be a little active in their vocabulary learning when about nearly half of them had ever known self-initiated independent strategy to facilitate their learning. Guessing the meaning of unknown words was the second most frequently known strategies by first year students (context analysis: 49.29\%; analyzing parts of speech: 47.14\%; pictures, gestures: 47.14\%; word-structure analysis: 45.71\%). This ranking (although it is far away from first two groups' priority) was hardly surprising when average second language learners face a serious challenge in trying to master the words they need in order to communicate in the language. Therefore, they should be more inclined to guess the meaning of unknown words because this appears to be the only possible way for acquiring an unlimited number of vocabulary items or for discovering the meaning of words in examinations when dictionaries and references are not allowed. It is remarkable that a large number of students were not familiar with the strategy of "asking for synonyms or paraphrases" (32.86\%). And only 9.29\% of students used "monolingual dictionaries".

Second, in order to enrich their vocabulary knowledge, the students needed a way to memorize what they had learned as described in question 16. Generally, the results from the questionnaire indicate that the strategies the student subjects ever knew for vocabulary retention were written repetition; spoken repetition and word list $(72.14 \%, 60.71 \%$, and $60.00 \%$ respectively). More than half of students believed that these strategies were effective for memorization. A smaller proportion of approximately $50 \%$ of the students reported that they remembered vocabulary by word family (47.86\%); and pictures, illustrations (40.71\%). Therefore, it can be said that this finding challenges the conclusion reached by $\mathrm{Gu}$ and Johnson (1996) who identify memory strategies as the least frequently used vocabulary strategies. However, these students seemed to lack the skills to apply their vocabulary in real situations although they are considered as the most dominant ways to remember words. These strategies appeared to be at the bottom of the list of ways to retain the knowledge of vocabulary with the percentage of $30.71 \%$ for "word in sentence or context" and $25.71 \%$ for "daily conversation".

Finally, if the first two categories are partly related to vocabulary learning strategies in class, the third one in question 17 involves self-directed or classroom independent vocabulary learning strategies. The students once more seemed to lack the skills to enrich their vocabulary for real situations although they are considered as the most dominant ways to expand words. The students reported high familiarity to two strategies: seeing films with subtitles and listening to songs (77.86\% and $70.71 \%$ respectively). This can be explained by the very high percentage of the students just wanted to learn a vocabulary item when they considered it interesting, or nearly as many as that number of students stated that they learned vocabulary when they felt like to do so. Besides, students reported medium familiarity to surfing net for information (51.43\%); doing exercises on the internet or outside school program $(51.43 \%)$. The strategies that were reported being stranger than any other strategy were learning how to use different kinds of dictionaries $(34.29 \%)$; Vietnamese-English translation or vice versa (34.29\%); conversations with friends, teachers or native speaker (29.29\%); reading newspaper or magazines $(27.86 \%)$; listening to the radio or watching TV $(24.29 \%)$; games $(10.71 \%)$; and parttime jobs for practicing English (9.29\%).

In a nutshell, the first year students of University of Finance-Marketing reported high familiarity to using bilingual dictionary, asking for L2>L1 translation when they first encountered a word; or written repetition, spoken repetition and word list for vocabulary retention. The majority of these respondents' predominant belief might be that relying on 
Vietnamese could make them sure that they knew the word, was effective for memorization and resulted in better learning of vocabulary items. Seeing films with subtitles and listening to songs in order to expand vocabulary by themselves can be partly explained by the fact that the very high percentage of the students just wanted to learn a vocabulary item when they considered it interesting, or nearly as many as that number of students stated that they learned vocabulary when they felt like to do so. As such, these findings for the second research question could count for the students' lack of confidence as well as partly explain why when facing with English native speakers; these students were rather resistant to initiate a talk. That was due to the lack of vocabulary and skills in applying known words in real situations and expanding vocabulary independently. It can be seen that what students did as part of their self vocabulary learning was simply trying to memorize words, and revising them regularly for the main purpose of doing exercises and taking final exams at school.

Findings for research question 3: What strategies are frequently used by the teachers in order to nurture learner autonomy in learning vocabulary for the first year students of University of Finance-Marketing?

Question 18 asked students what their teachers usually did to help them learn vocabulary in class. Their teachers were also involved in this question in their questionnaire (question 11 in teacher version of the quesionnaire). Data reveal that traditional methods such as read the word, give definition were really popular, although these methods should be gradually limited to move towards more learners' independence. There was really a mismatch in comparison between the teachers' and the students' responses. Among the items suggested in the questionnaire, "read and give synonyms and paraphrases" was the most frequently chosen method by the teachers while the students' choice for this method experienced second $(69.29 \%)$, behind the most frequently chosen one: "read the word and give Vietnamese definition" (77.86\%). In addition, the teachers reported that they did usually analyze parts of speech or word structure $(93.31 \%)$ when they instructed their students to learn vocabulary; but the students just reported about medium (49.29\%). Also, it is remarkable that the number of checks by the students for giving examples (37.14\%), using context analysis (34.29\%), organizing games and songs to motivate students to learn vocabulary $(10.00 \%)$ were always lower than the checks by the teachers $(69.23 \%, 61.54 \%$, and $23.08 \%$ respectively).

The result obtained from both questionnaires for this question pointed out that the frequency of Vietnamese use in class was still high. Many of teachers still usually used Vietnamese to explain the meaning of new words. And using context in teaching vocabulary or analyzing parts of speech or word structure was not focused when the students were at school. These matters can be justified by the facts that the students always considered vocabulary learning as difficult, they were not very confident about their vocabulary and time for vocabulary dealing at class was limited, thus the teachers' using Vietnamese to give the definition of English new words frequently could make students have a secure feeling that they "knew" the word when comprehending its meaning in mother tongue. In addition, the mismatch between the teachers' and the students' responses showed one paradox that the teachers could believe what they did was the best; however, in reality, the students surveyed thought the opposite things or they could not acquire much from what their teachers did for them.

Question 19 in the students' questionnaire and 12 in the teachers' questionnaire show their demonstrations in greater details what the teachers did to nourish student autonomy in enriching vocabulary. What the teachers reported to do in the data really gives a general impression that the teachers did try to do a good job in promoting learner autonomy to their students. And the students' responses also show positive results that the teachers did help them to be aware of their active role in the success of vocabulary learning. However, there was a divergence between them. For teachers' reports, giving students opportunities to take control of their own learning; helping students to be aware of the role of autonomy in vocabulary learning; encouraging interaction and group work; and encouraging students to learn at home were four top frequent techniques they usually employed (from $92.31 \%$ to 100\%). The students, on the other hand, reported much lower percentage for these items (from $61.43 \%$ to $73.57 \%$ ). Also, not many students from the sample claimed they received their teachers' introduction of ways to learn autonomously or building up confidence (47.14\% and $45 \%$ respectively) although their teachers reported on those very positively (84.62\% and $69.23 \%$ respectively). Advising students to read books, newspapers, etc. experienced the same situation $(67.14 \%$ versus $76.92 \%)$. All these data once more indicates one paradox that the teachers could believe what they did was the best; however, in reality, the students surveyed thought the opposite things or they could not acquire much from what their teachers did for them. The only item that was more chosen by the students than the teachers was the teachers' helping students reflect on their learning process (teachers reported $53.85 \%$ while students $79.29 \%$ ). This can be explained by the fact that the students were afraid of their teachers' assignments or mini-tests.

In brief, the students acknowledged the activities held by their teachers to help them learn vocabulary and develop learner autonomy in vocabulary learning although the teachers' efforts should be more highly appreciated in promoting a collaborative learning environment, encouraging and providing information regarding students' self-study. More importantly, it has been noted about teachers' willingness to gradually give authority and control in teaching-learning process to the students. However, the frequency of Vietnamese use at class was still high. Using context in teaching vocabulary or analyzing parts of speech or word structure was not much focused when the students were at school. Playing games and singing songs were the least frequent activities though students seemed to be easily motivated to learn vocabulary through these activities. A paradox that the teachers could believe what they did was the best; however, 
in reality, the students surveyed thought the opposite things or they could not acquire much from what their teachers did for them should be paid attention for better teaching and learning results.

In terms of teachers' difficulties in guiding students to learn vocabulary autonomously in question 13 in the teachers' questionnaire, all of the teachers at University of Finance-Marketing considered students' inactiveness in study as their top trouble in helping students learn vocabulary. This is not a surprise because we can see from the above discussion that the students had the habit to depend on teachers' explanations. Students' motivation was also one out of three troubles for teachers $(61.54 \%)$. This was proved in the responses of the first research question that although students' intrinsic motivation did exist, it did not last long. Rather, it could be triggered if the students were exposed to interesting and communicative materials. Students' English knowledge in general holds a small proportion in the suggested difficulties to teachers $(23.08 \%)$. This might be due to the students' long previous experience of learning English at high school.

\section{CONCLUSION}

The study indicates that the majority of these students' predominant belief might be that relying on Vietnamese could make them sure that they knew the word, was effective for memorization and resulted in better learning of vocabulary items. As such, this could count for the students' lack of confidence as well as partly explain why when facing with English native speakers; these students were rather resistant to initiate a talk. That was due to the lack of vocabulary and skills in applying known words in real situations and expanding vocabulary independently. It can be seen that what students did as part of their self-vocabulary learning was simply trying to memorize words, and revising them regularly for the main purpose of doing exercises and taking final exams at school. Thus, the result of this study aims at raising the students' awareness of using more vocabulary learning strategies, and motivating them to choose the most suitable vocabulary learning strategies to help them become high-performing learners.

\section{REFERENCES}

[1] Benson, S.I. (2001). Freedom, autonomy and the concept of the person. Oxford: Oxford University Press.

[2] Coady, J. (1997). L2 vocabulary acquisition through extensive reading. In J. Coady \& T. Huckin (Ed.), Second Language Vocabulary Acquisition (pp. 225-237). Cambridge: Cambridge University Press.

[3] Gu, Y.Q., and Johnson, R.K. (1996). Vocabulary learning strategies and language learning outcomes. Language Learning, 46(4), 643-679.

[4] Hunt, A., \& Beglar, D. (2002). Current research and practice in teaching vocabulary learning. In J.C. Richard, \& W.A. Renandya (Ed.), Methodology in Language Teaching: an Anthology of Current Practice (pp255-266). Cambridge: Cambridge University Press.

[5] Krashen, S.D. (1989). Principles and Practice in Second Language Acquisition. English Language Teaching series. London: Prentice-Hall International (UK) Ltd.

[6] Nation, I.S.P. (1990). Teaching and learning vocabulary. Massachusetts: Heinle \& Heinle Publisher.

[7] Nation, I.S.P. (2001). Learning vocabulary in another language. Cambridge: Cambridge University Press.

[8] Nunan, D. (1997). Designing and adapting materials to encourage learner autonomy. London: Longman, p. 193.

[9] Nunan, D. (1999). Second language teaching and learning. Massachusetts: Heinle \& Heinle Publisher.

[10] Nunan, D. (2000). Autonomy in Language Learning. Hong Kong: Hong Kong University Press.

[11] Scharle, A., \& Szabo, A. (2000). Learner autonomy - A guide to developing learner responsibility. Cambridge University Press.

[12] Schmitt, N. (1997). Vocabulary learning strategies. In N. Schmitt \& M. McCarthy (Eds.). Vocabulary: Description, acquisition and pedagogy (pp. 199-227). Cambridge: Cambridge University Press.

[13] Schmitt, N. (2000). Vocabulary in language teaching. Cambridge: Cambridge University Press.

[14] Sokmen, A. (1997). Current trends in teaching second language vocabulary. In N. Schmitt \& M. McCarthy (eds.), Vocabulary: Description, Acquisition and Pedagogy. (pp.237-257). Cambridge: Cambridge University Press.

[15] Thanasoulas, D. (2000). What is learner autonomy and how can it be fostered? Retrieved August 12,2010 from http://iteslj.Org/Articles/Thanasoulas_Autonomy.html.

Luu Trong Tuan is currently an EFL teacher at Ho Chi Minh City University for Natural Resources and Environment. He received his M.TESOL from Victoria University, Australia in 2004. Besides his focus on TESOL, his recent publications such as Language Transfer is Cultural Transfer between Communities, Social Sciences Review, No. 11, 2004, pp. 60-63; and Principles for Scientific Translation, Social Sciences Review, No. 8, 2004, pp. 63-67; and Building Vietnamese Medical Terminology via Language Contact, Australian Journal of Linguistics, Vol. 29, No. 3, September 2009, pp. 315-336 show his interest in language contact and translation areas. 